\title{
Análise microbiológica de águas de reservatórios da comunidade do Lixão de Gramacho/Rio de Janeiro
}

A importância de tratar das questões que implicam na saúde da população da Comunidade do lixão do Jardim Gramacho, assim como a água de consumo próprio o presente artigo é parte integrante dos resultados da dissertação de mestrado em Ciências do Meio Ambiente, cujo objetivo geral foi: Analisar os padrões Microbiológicos da água utilizada pela população da comunidade do lixão. Os resultados revelaram que, nas placas Agar SS, houve presença de Salmonella em $70 \%$, e Shigella $90 \%$ na água dos reservatórios, já em 95\% das placas Agar Chromocult, houve presença de Escherichia coli e Coliformes Totais, vale destacar que apenas uma amostra colhida no reservatório da casa 06 negativou para todos os agentes. Conclui-se que, a maioria dos reservatórios que armazenam a água de consumo próprio dos moradores, influenciam negativamente na saúde da população, podendo ocasionar diversas doenças de veiculação hídrica. Sendo assim, fazse necessário que medidas sejam adotadas para a melhoria da qualidade de vida e saúde dessa comunidade.

Palavras-chave: Análise Microbiológica; Reservatórios de Água; Comunidade do Lixão; Jardim Gramacho; Rio de Janeiro.

\section{Microbiological analysis of water reservoirs of the population of Lixão de Gramacho/Rio de Janeiro}

\begin{abstract}
The importance of addressing the issues that imply the health of the community population of the Jardim Gramacho dump, as well as the water for own consumption, this article is an integral part of the results of the master's thesis on Environmental Sciences, whose general objective was: Analyze the Microbiological standards of the water used by the population of the dump community. The results showed that, in the SS agar plates, there was presence of Salmonella in $70 \%$, and $90 \%$ Shigella in the water of the reservoirs, already in $95 \%$ of Chromocult Agar plates, Escherichia coli and Total Coliformes were present, it is worth noting that only a sample collected in the reservoir of house 06 failed for all agents. It is concluded that, most of the reservoirs that store the water of the residents' own consumption, negatively influence the health of the population, being able to cause several waterborne diseases. Therefore, it is necessary that measures be adopted to improve the quality of life and health of this community.
\end{abstract}

Keywords: Microbiological Analysis; Water reservoir; Community of the Garbage; Jardim Gramacho; Rio de Janeiro.

Topic: Desenvolvimento, Sustentabilidade e Meio Ambiente

Reviewed anonymously in the process of blind peer
Received: 10/02/2019

Approved: 25/03/2019
Milton Domingues da Silva Junior (iD Universidade Veiga de Almeida, Brasil http://lattes.cnpq.br/1750194036067887 http://orcid.org/0000-0003-1163-9005 milton.enf.saude@bol.com.br

Saulo Roni Moraes (iD

Universidade Veiga de Almeida, Brasil http://lattes.cnpq.br/4391912101295773

http://orcid.org/0000-0002-8015-408X sauloroni@gmail.com

Izabella Christynne Valadão ii

Universidade Veiga de Almeida, Brasil http://lattes.cnpq.br/5095473477830624

http://orcid.org/0000-0002-8522-0680

izavaladao5@gmail.com
Wagner de Souza Pereira

Universidade Veiga de Almeida, Brasi http://lattes.cnpq.br/4831334377580644 http://orcid.org/0000-0002-0581-9360 pereiraws@gmail.com

Viviane Bernardes dos Santos Miranda Universidade Estadual de Maringá, Brasil http://lattes.cnpq.br/7444746454207037 http://orcid.org/0000-0002-5571-8293 v.bernardesbio@gmail.com
Referencing this:

SILVA JUNIOR, M. D.; MORAES, S. R.; VALADÃO, I. C.; PEREIRA, W. S.; MIRANDA, V. B. S.. Análise microbiológica de águas de reservatórios da comunidade do Lixão de Gramacho/Rio de Janeiro. Revista Ibero Americana de Ciências Ambientais, v.10, n.2, p.234-242, 2019. DOI: http://doi.org/10.6008/CBPC2179-6858.2019.002.0020 


\section{INTRODUÇÃO}

O lixão é conceituado como um depósito de resíduos ou rejeitos in natura, originados da construção civil, hospitalar, doméstico, industrial, dentre outros. Compreendem áreas que recebe o lixo sem manejo ou preparação adequada, provocando a degradação, poluindo as águas superficiais e subterrâneas, o ar, o solo e proliferando a geração de vetores ameaçando o que está em seu entorno (WALDMAN, 2013).

Diante deste contexto, encontra-se o lixão de Gramacho, que fica localizado na região metropolitana da baixada Fluminense do estado do Rio de Janeiro, o qual é marcado por bolsões de miséria, sem instalação de infraestrutura básica, tal como saneamento básico, pavimentação, abastecimento de água, energia elétrica e disponibilização de rede de esgoto, o que apresenta diversos e graves problemas de cunho socioambiental, a exemplo: o intenso e frequente tráfico de entorpecentes, a ausência de segurança pública e limpeza urbana básica, e atrelados a atividades poluidoras com impactos elevados em todas as suas vertentes - no ar como um dos principais emissores de gás de efeito estufa, e no solo e na água, através do lixiviado permeado, tornando se modelo clássico de injustiça socioambiental (BASTOS et al., 2016)

De acordo com Duarte (2018), alguns estudos evidenciam uma queda quanto à existência de alguns lixões, embora, os que estão ativos, ainda é uma realidade encontrada em muitos lugares, causando danos a população a qual está exposta e impactos de cunho socioambientais, devido a liberação de elementos químicos, agentes patogênicos gravemente danosos a saúde humana e ao meio ambiente, principalmente a contaminação do lençol freático, tais resultados são preocupantes, pois, quando se trata de um lixão desativado, o mesmo permanece como um agente poluidor por cerca de 15 anos.

O mesmo autor afirma que, diante desse cenário, quando se trata de contaminação do solo, do lençol freático e das águas, um dos principais agravantes é o chorume, uma vez que pode alcançar as camadas mais profundas do solo, ocasionando um fluxo de escoamento lateral para um determinado ponto, onde é descarregado na superfície misturando com as águas da chuva e nascentes, transportando uma série de compostos químicos e biológicos afetando a população do lixão.

Jacob et al. (2017) afirmam que a água é por excelência o elemento de transversalidade, que realiza a medição entre céu e terra por meio de sua ação comunicativa nas interações celulares e sua presença nos processos circulatórios dos seres vivos e do próprio planeta terra, ela é um dos mais importantes recursos ambientais e sua adequada gestão, é componente fundamental da política ambiental, quando as pessoas não têm acesso a água potável no lar, ou enquanto recurso produtivo, suas escolhas e liberdades são limitadas pela doença, pobreza e vulnerabilidade.

Para Mendonça et al. (2017), a água é considerada um recurso natural e insubstituível para a manutenção da vida, e o seu controle é uma necessidade universal, o que exige grande atenção das autoridades sanitárias e dos consumidores em geral, sobretudo, no que se refere à água destinada ao consumo humano, a mesma pode tornar um veículo de transmissão de agentes patogênicos e substâncias nocivas, influenciando diretamente na saúde da população, principalmente aos que vivem ao entorno de lixões. 
Segundo a Portaria no 2.914 (BRASIL, 2011) do Ministério da Saúde, ela estabelece normas de qualidade da água para consumo humano. No capítulo IV desta norma consta que: a água potável destinada ao consumo humano, precisa atender aos padrões de potabilidade, incluindo parâmetros microbiológicos, físicos, químicos e radioativos, não oferecendo riscos à saúde.

Segundo Jacob et al. (2017), as pessoas que vivem no lixão, estão expostas aos riscos, devido à incapacidade em lidar com as ameaças externas, estando suscetíveis as consequências negativas pela falta de acesso à água segura, de higiene e de saneamento, enquanto direito humano. Assim, como a pobreza, a exclusão e a vulnerabilidade são interligadas, pessoas que vivem em pobreza crônica, tem acesso muito precário à água segura, ao saneamento, à higiene, ao ensino, à saúde e aos serviços sociais, além disso, vivem em áreas sujeitas a degradação ambiental contribuindo com a vulnerabilidade e as impedido de sair da situação de pobreza.

De acordo com o Ministério das cidades, cerca de 60 milhões de brasileiros (9,6 milhões de domicílios urbanos) não são atendidos pela rede de coleta de esgoto e, 15 milhões (3,4 milhões de domicílios) não tem acesso à água encanada. 0 alarmante é a informação de que, apenas $25 \%$ do esgoto é tratado e o restante despejado "in natura" nos rios e no mar sem tratamento algum, e devido esse déficit de tratamento, $65 \%$ das internações hospitalares no país é ocasionado devido às doenças transmitidas pela água, como por exemplo, as disenterias, hepatites, meningites, ascaridíases, tracomas, esquistossomose entre outras. Segundo a Organização Mundial da Saúde, (OMS), mais de cinco milhões de pessoas morrem por ano no mundo (número equivalente a população de um país como a Finlândia) devido as doenças transmitidas pela água (BRASIL, 2017).

Diante do exposto, é visto que a população do lixão, encontram-se diretamente suscetível aos agravos a saúde, devido um meio ambiente inadequado e interligados há grandes fatores prejudiciais, que possam comprometer diretamente na qualidade de vida e subsistência, assim como a utilização da água para o consumo. Visto que, a água quando não tratada, é propícia há transmissão de agentes patológicos como vírus e bactérias, então, é necessário realizar a análise da mesma, e medidas sejam tomadas para a conscientização dessa comunidade.

O objetivo geral do trabalho foi: Analisar os Padrões Microbiológicos da água utilizada pela Comunidade do Lixão do Jardim Gramacho em Duque de Caxias - Rio de Janeiro, no período de Dezembro de 2018. Os objetivos específicos foi identificar a presença e ausência de microrganismos de veiculação hídrica, tais como: Salmonella; Shigella; Eschechiria Coli e Coliformes Totais.

\section{MATERIAIS E MÉTODOS}

As amostras de água foram coletadas no dia 04 de dezembro de 2018, em reservatórios d'água na comunidade do campinho do lixão de Gramacho, em 04 lotes, onde, cinco casas em cada lote, foram escolhidas aleatoriamente para a realização dos procedimentos.

A técnica destinada para a coleta do material, foi o uso de toca para proteção capilar, óculos, máscara cirúrgica, capote e técnica estéril, como o uso de luvas estéreis, seringas de $10 \mathrm{ml}$, e frascos estéreis de 70 
$\mathrm{ml}$ para o armazenamento das amostras. Em cada reservatório, foi aspirado um total de $70 \mathrm{ml}$ de amostra d'água e logo colocadas dentro de frascos estéreis, após o seu fechamento, cada recipiente foi identificado de acordo com suas respectivas amostras, e colocadas em caixa de isopor com gelo reciclável e bolsas de ar, e lacrado com fita adesiva,

O material foi destinado para a Universidade Veiga de Almeida - Campus Tijuca, situada no Município do Rio de Janeiro, e armazenado em geladeira própria para material biológico, entre temperatura de +2 a $+8^{\circ} \mathrm{C}$ no laboratório de Microbiologia da Universidade. Para a análise, utilizou-se placas de meios de culturas prontas para a leitura dos microrganismos. Com o intuito de detectar os patógenos da Salmonella e Shigella, foi utilizada a Placa Agar SS de 90mm, em forma de gel, viscosidade firme de cor vermelho alaranjado, $\mathrm{pH}$ de 7,0, com $20 \mathrm{ml}$ de meio de cultura em sua composição. As placas Agar SS apresentavam o número de referência:1060 e Registro da ANVISA/MS 80035670010, Lote:MIC1811395, com fabricação em 29/10/2018 e validade até $27 / 01 / 2019$.

Para a identificação de Escherichia Coli e Coliformes Totais, utilizou a placa Agar Chromocult de $49 \mathrm{~mm}$, em forma de gel e viscosidade firme, coloração Âmbar claro e pH de 6,8, com $8 \mathrm{ml}$ de meio de cultura. As placas Agar Chromocult apresentavam o número de referência: 3522 e Registro da ANVISA/MS 80035670010, Lote:MIN1804172, com fabricação em 06/11/2018 e validade até 05/05/2019.

As placas Agar SS receberam 1ml de água, e as Agar Chromocult 100ul de amostra, sendo espalhadas pelo meio de cultura com o auxílio de pipetas estéreis e graduadas, para cada placa, utilizou-se uma pipeta, com a finalidade de não ocorrer sobreposição de agentes nas amostras, logo, as amostras foram colocadas em estufa microbiológica do Modelo Deleo - Equipamentos Laboratoriais e ajustada a temperatura de 37으, no prazo de 24 horas para a leitura dos materiais.

\section{RESULTADOS}

Após ter completado as 24 horas, a incubadora foi desligada, e todas as placas guardadas na geladeira para a futura análise. No dia 10 de Dezembro de 2018, as placas foram retiradas da geladeira, e colocadas sob a bancada do laboratório de microbiologia. Cada placa foi observada criteriosamente, através do aparelho COLONY-COUNTER, provido de lupa e iluminação para a identificação de presença e ausência dos agentes pesquisados, os resultados quando observados nas placas, quanto a presença de Salmonella, destacaram as colônias incolores de centro negro, e Shigella colônias pequenas e incolores. Nas placas Agar Chromocult, destacaram para E. coli, colônias de coloração roxa, e Coliformes Totais colônias rosas apresentadas na figura 1. 


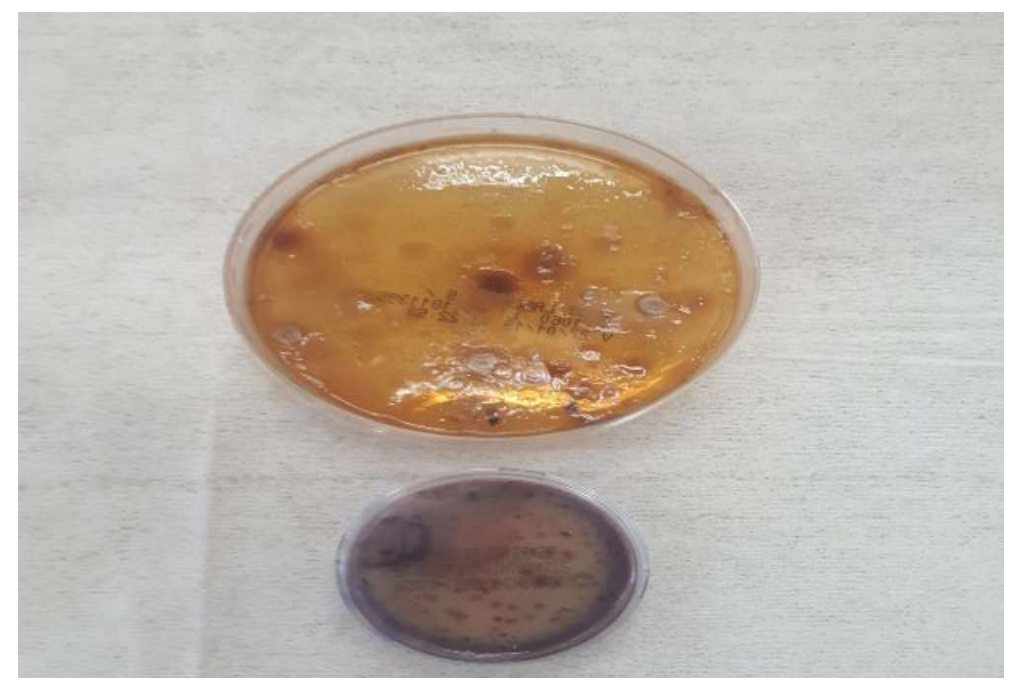

Figura 1: Resultado do Crescimento Microbiano nas amostras de água nas placas.

\section{DISCUSSÃO}

Os resultados observados nas placas de meio de cultura Agar SS, das amostras coletadas nos reservatórios da comunidade mostraram que, em 14 (70\%) foram detectadas Salmonella e 6 (30\%) não apresentaram o crescimento da bactéria em C2 no lote 01, nas C6, C7 e C10 no lote 02, e lote 03, C11 e C12. Diante desses achados, visto que essa comunidade vive de forma precária e condições higiênicos sanitárias insuficientes, é notório que o grande percentual de crescimento de Salmonella nas amostras d'água, torna se preocupante, devido ao potencial agravante na saúde dos moradores do lixão, e assim, podendo desenvolver as formas graves da doença por esse agente patógeno.

Tabela 1: Resultados das análises microbiológicas da água dos reservatórios da comunidade do Campinho do lixão de Gramacho em Duque de Caxias/RJ.

\begin{tabular}{|l|l|l|l|l|l|}
\hline AMOSTRAS & LOTE & SALMONELLA & SHIGELLA & E. COLI & COLIFORMES TOTAIS \\
\hline CASA 1 & LT1 & PRESENTE & PRESENTE & PRESENTE & PRESENTE \\
\hline CASA 2 & LT1 & AUSENTE & PRESENTE & PRESENTE & PRESENTE \\
\hline CASA 3 & LT1 & PRESENTE & PRESENTE & PRESENTE & PRESENTE \\
\hline CASA 4 & LT1 & PRESENTE & AUSENTE & PRESENTE & PRESENTE \\
\hline CASA 5 & LT1 & PRESENTE & PRESENTE & PRESENTE & PRESENTE \\
\hline CASA 6 & LT2 & AUSENTE & AUSENTE & AUSENTE & AUSENTE \\
\hline CASA 7 & LT2 & AUSENTE & PRESENTE & PRESENTE & PRESENTE \\
\hline CASA 8 & LT2 & PRESENTE & PRESENTE & PRESENTE & PRESENTE \\
\hline CASA 9 & LT2 & PRESENTE & PRESENTE & PRESENTE & PRESENTE \\
\hline CASA 10 & LT2 & AUSENTE & PRESENTE & PRESENTE & PRESENTE \\
\hline CASA 11 & LT3 & AUSENTE & PRESENTE & PRESENTE & PRESENTE \\
\hline CASA 12 & LT3 & AUSENTE & PRESENTE & PRESENTE & PRESENTE \\
\hline CASA 13 & LT3 & PRESENTE & PRESENTE & PRESENTE & PRESENTE \\
\hline CASA 14 & LT3 & PRESENTE & PRESENTE & PRESENTE & PRESENTE \\
\hline CASA 15 & LT3 & PRESENTE & PRESENTE & PRESENTE & PRESENTE \\
\hline CASA 16 & LT4 & PRESENTE & PRESENTE & PRESENTE & PRESENTE \\
\hline CASA17 & LT4 & PRESENTE & PRESENTE & PRESENTE & PRESENTE \\
\hline CASA 18 & LT4 & PRESENTE & PRESENTE & PRESENTE & PRESENTE \\
\hline CASA 19 & LT4 & PRESENTE & PRESENTE & PRESENTE & PRESENTE \\
\hline CASA 20 & LT4 & PRESENTE & PRESENTE & PRESENTE & PRESENTE \\
\hline
\end{tabular}

Cunha et al. (2017) afirmam que a Salmonelose é uma doença bacteriana aguda, de distribuição mundial, e está associada aos baixos níveis socioeconômicos em áreas com precárias condições de saneamento, higiene pessoal e ambiental, e tem como reservatório principal o homem, sua transmissão é 
através do contato direto com as mãos do doente ou portador, contato indireto relacionado à água e aos alimentos contaminados pelas fezes e urina dos doentes. Os fatores extrínsecos aos alimentos, com destaque os relacionados ao meio ambiente, tais como temperatura e umidade existentes nos sítios de conservação, armazenamento, produção, comercialização e seu consumo, também interferem de modo significativo, no crescimento e viabilidade da Salmonella.

Os autores ainda destacam que, um dos maiores problemas relacionados a Salmonenose é a febre tifoide, que acomete as pessoas apresentando sinais e sintomas clássicos como febre alta, cefaleia, dor abdominal, anorexia, roséolas tificas, entre outros problemas, ainda, em maior grau a enterorragia que acomete em 3 a 10\% dos casos, a perda sanguínea é variável e pode ser volumosa, já a perfuração intestinal é a complicação mais temida em virtude da gravidade, ocorre em $3 \%$ dos casos, surgindo por volta do 20 은 dia da doença, particularmente nas formas mais graves e tardiamente diagnosticadas.

Quando verificado as amostras para Shigella, os resultados demonstraram presença em $18(90 \%)$ das placas e $2(10 \%)$ estavam ausentes em C4 lote 01 e C6 no lote 02. Esses achados elevados de Shigella, demonstram o grande risco para desinteria bacilar na população, diante da problemática, foi relatado entre os moradores do lixão.

Segundo Cunha et al. (2017) a Shigella é a principal causa da desinteria bacilar, causando inflamação do trato gastrointestinal, também transmitida por via fecal-oral, consumo de alimentos e principalmente através água contaminada, devido sua relação com à falta de higiene e deficiência de saneamento básico, está entre uma das maiores responsáveis pela morbidade e mortalidade em populações de alto risco, como crianças menores de cinco anos e idosos.

Para tal, os mesmos relatam que no Brasil, existem poucos estudos sobre a presença de Shigella na água e alimentos contaminados, e que a falta desses relatos sobre a doença, procede da Shigella apresentar características fenotípicas semelhantes às da Salmonella, possibilitando que os surtos de Shigella sejam atribuídos à Salmonella.

Vale destacar que, para a identificação da Shigella, as placas Agar SS apresentavam meios de cultura próprio, exclusivamente para o crescimento desse agente em amostras d'água, então, os resultados corroboram com novos estudos, e afirmam que a Shigella pode ser encontrada nas amostras de água, analisadas separadamente dos agentes da Salmonella.

Ao analisar as placas Agar Chromocult, especificamente para a identificação de Eschechiria Coli e coliformes totais, foi evidenciado em 19 (95\%) a presença de E. coli e 1(5\%) a ausência da mesma na C6 do lote 02. Segundo o Ministério da Saúde, a E. coli é uma bactéria encontrada naturalmente no intestino de animais e humanos, considerada como um coliforme fecal e em alta quantidade, indica contaminação por fezes e esgoto doméstico causando graves doenças, como a enterohemorrágica, apresentando cólicas abdominais severas, diarreia sanguinolenta, seguido de vômitos e febres (BRASIL, 2013).

Para Tortora et al. (2012), apesar da maior parte ser inofensiva, existem algumas linhagens de $E$. coli que são patogênicas, causando a gastroenterite, sendo a patogenicidade conferida pela presença de fímbrias especializadas que permitem que elas se fixem ao epitélio intestinal, e pela produção de toxinas. As que 
produzem toxinas, está a enterotoxigênica não-invasiva, produtora de uma enterotoxina que causa a diarreia dos viajantes, produzindo fezes aquosas. Outro integrante patogênico é a E. coli enteroagregativa que, como o próprio nome especifica, são agregadas umas às outras no sistema gastrintestinal. Já a E. coli enteroinvasiva invade a mucosa intestinal, podendo causar disenteria, febre e inflamação. Os autores destacam que, a $E$. coli patogênica mais perigosa é a enterohemorrágica, que além de se aderir à mucosa intestinal, produz a toxina Shiga, que causa inflamação do colo (colite hemorrágica), com eliminação de sangue nas fezes.

Os resultados alarmantes quanto a presença de E. coli nas amostras, indicam que a água de consumo dos moradores está completamente contaminada, o que indica a contaminação por fezes e esgoto doméstico, podendo desenvolver as formas graves da doença. Portanto, é observado que a situação local, é favorável para a contaminação de E. coli na água, devido à falta de estrutura, assim como, a captação irregular de água nas mangueiras, que ficam expostas ao esgoto local, águas superficiais advindas da chuva, que consequentemente infiltram o solo, emergindo os agentes advindos do solo contaminados pelo lixão, interferindo na qualidade da água.

Duarte (2018) relata que, quando se trata de contaminação do solo, do lençol freático e das águas, o chorume é um dos principais agravantes, o que pode alcançar as camadas mais profundas do solo, causando um fluxo de escoamento lateral para um determinado ponto, onde é descarregado na superfície misturando com as águas da chuva e nascentes, transportando uma série de compostos químicos e biológicos afetando a população do lixão.

Nunes (2018), ainda em seu estudo, quanto a análise microbiológica da água em rede pública de abastecimento, identificou que $14,46 \%$ das amostras estavam contaminadas por $E$. coli, já em relação as amostras retiradas de reservatórios d'água, apresentou um nível mais elevado de contaminação de $E$. coli quando comparadas com às da rede, com $18,07 \%$, observou que tanto a água da rede de abastecimento, quanto a armazenada em reservatórios domiciliar, possuem altas taxas de contaminação, o que pode ocorrer não somente pela limpeza e manutenção inadequada dos reservatórios, mas também pelas fontes de captação.

A presença de Coliformes Totais foi identificada em 19 (95\%) das amostras e somente 1(5\%) ausente em C6, esse resultado para a contaminação por Coliformes Totais, reforça a hipótese de que os reservatórios exercem influência negativa na água armazenada e consumida pelos moradores. Segundo a Brasil (2013), os Coliformes Totais são bactérias do grupo coliforme e possuem bacilos gram-negativos, aeróbios ou anaeróbios, a maioria das bactérias pertencem aos gêneros Escherichia, Citrobacter, Klebsiella $e$ Enterobacter, embora vários outros gêneros e espécies pertençam a esse grupo.

Macedo et al. (2018), realizaram um estudo no Município do Vale do Taquari no Rio grande do Sul, em poços da região, identificaram que na primeira amostragem, $53 \%$ dos poços apresentaram resultados positivos para coliformes totais, o que indica que o sistema de distribuição estava inadequado, sendo assim, a presença desses agentes indica alguma fonte de contaminação.

Richter (2013) relata que a presença de coliformes aponta a possibilidade de contaminação deste recurso por esgotos domésticos e, nem sempre toda água que apresenta coliformes é infectada, assim 
podendo veicular doenças de origem hídrica. Macedo et al. (2018), no mesmo estudo, quanto a presença de coliformes termotolerantes, verificaram na primeira amostragem em $40 \%$ dos poços, já na segunda amostra $80 \%$ apresentaram resultados positivos para este tipo de contaminante, no entanto, destacam que as bactérias pertencentes deste grupo, geralmente habitam o trato intestinal dos animais de sangue quente, sendo consideradas como indicadoras da contaminação de água por fezes e possibilitam a disseminação de grande parte das doenças de veiculação hídrica transmitidas via fecal-oral, deste modo, esses organismos patogênicos alcançam o ambiente aquático, sendo capazes de ocasionar uma contaminação nas pessoas que utilizam desta água.

Ressaltando Nunes (2018), com relação as amostras verificadas em caixa d'agua, 63,86\% estavam contaminadas por coliformes totais, contaminação maior que as encontradas na rede de abastecimento determinadas em $43,37 \%$, com esses resultados observou que tanto a água proveniente da rede de abastecimento, quanto a água armazenada nos reservatórios domiciliares, possuem altas taxas de contaminação por grupo dos coliformes.

Conforme a Portaria do Ministério da Saúde, no 2914, de 2011, a água para consumo humano deve estar ausente de agentes patógenos como a Eschechiria Coli e Coliformes Totais em $100 \mathrm{ml}$ de água, tanto na saída de tratamento como no sistema de distribuição da água. De acordo com os achados no estudo, é visto que os padrões de qualidade da água consumida pela população da comunidade, não estão de acordo com a Portaria supracitada, referentes aos Coliformes totais e E. coli, o que influencia na qualidade da ingestão de água, desencadeando doenças.

Mendonça (2017) afirma que, a água é considerada um recurso natural insubstituível para a manutenção da vida, e o seu controle é uma necessidade universal, o que exige atenção das autoridades sanitárias e dos consumidores em geral, sobretudo, no que se refere à agua destinada ao consumo humano, a mesma pode tornar um veículo de transmissão de agentes patogênicos e substâncias nocivas, influenciando diretamente na saúde da população.

Jacob et al. (2017) ressaltam que água é um dos mais importantes recursos ambientais e sua adequada gestão é componente fundamental da política ambiental, quando as pessoas não têm acesso a água potável no lar, ou enquanto recurso produtivo, suas escolhas e liberdades são limitadas pela doença, pobreza e vulnerabilidade, assim, o acesso restrito à água e ao saneamento básico configura uma forma de privação que ameaça a vida, limita as oportunidades e enfraquece a dignidade humana, portanto, ela está intrinsecamente ligada a sobrevivência de todas as formas de vida e ao processo de desenvolvimento e culturas.

Diante deste contexto, é possível afirmar que, os moradores da comunidade estão suscetíveis as consequências negativas em todos os aspectos dentro do lixão, pela água que consomem, pela falta de higiene, pela falta de saneamento básico e a pobreza local, o que configura a vulnerabilidade e exclusão social dessa população. 


\section{CONCLUSÕES}

O presente estudo demonstrou que os reservatórios analisados na comunidade do lixão de Gramacho, exerceram efeitos negativos, quanto a análise microbiológica realizada, revelaram que a maioria estavam contaminadas por Salmonella, Shigella, Escherichia Coli e Coliformes Totais, essa problemática reflete na questão dos surtos de doenças, entre outras patologias que venham acometer essa comunidade, causando impactos na qualidade de vida da população e no consumo d'água, assim, é notório que os padrões microbiológicos analisados nos reservatórios, não estão de acordo com a Portaria 2914/11, quando retrata que a água de consumo humano devem estar ausentes de E. coli e Coliformes Totais em $100 \mathrm{ml}$ d'água. Então, torna-se importante garantir que as enfermidades sejam evitadas através de ações preventivas que envolvam não só a oferta de serviços de abastecimento de água, esgotamento sanitário e o manejo das águas de consumo, mas também por meio da promoção de educação sanitária e educação em saúde, na qual devese orientar a população da comunidade do lixão, adotarem hábitos higiênicos de ordem pessoal, alimentares e doméstico.

\section{REFERÊNCIAS}

BASTOS, V. P.; MAGALHÃES, A. O.. Lixão de Gramacho: impactos do encerramento para os catadores. Revista da Associação Brasileira de Ensino e Pesquisa Social, Brasília, v.16, n.31, p.379-398, 2016

BRASIL. Ministério da Saúde. Portaria n.2.914: Dispõe sobre os procedimentos de controle e de vigilância da qualidade da água para consumo humano e seu padrão de potabilidade. Brasília, 2011

BRASIL. Água: um recurso cada vez mais ameaçado. Brasília: MMA, 2017.

BRASIL. Fundação Nacional de Saúde. Manual Prático de Análise de Água. 4 ed. Brasília: FUNASA, 2013.

CUNHA, F. P. L..; VILELA, M. L. A. S.; MAXIMIANO, T.; BARBOSA, T. M. M.; GUIMARÃES, D. A. L.; TOLEDO, R. C. C.. Shigella spp.: um problema de Saúde Pública. Revista Higiene Alimentar, Ituiutaba, v.31, n.264-265, p.52-57, 2017.

DUARTE, M. B. C. P.. Os Impactos Socioambientais Decorrentes de Lixões: estudo de caso do sitio GulandimLimoeiro de Anadias. Dissertação (Mestrado em Geografia) Universidade Federal de Alagoas, Maceió, 2018.

JACOB, R. P.; GRANDISOLI, E.. Água e sustentabilidade, desafios, perspectivas e soluções. São Paulo: Reconectta, 2017.
MACEDO, T. L.; REMPEL, C.; MACIEL, M. J.. Análise FísicoQuímica e Microbiológica de Água de Poços Artesianos em um Município do Vale do Taquari/RS. Revista Tecnológica, Santa Cruz do Sul, v.22, n.1, p.58-65, 2018. DOI: http://dx.doi.org/10.17058/tecnology.v22i.10447

MENDONÇA, M. H. M.; ROSENDO, S. A. M.; CACHOEIRA, T. R. L.; SILVA, A. F. S.; JÁCOME, P. R. L. A.; JÁCOME JUNIOR, A. T.. Análise bacteriológica da água de consumo comercializada por caminhões pipa. Revista Ambiente Água, Taubaté, v.12, n.3, p.468-475, 2017. DOI: https://doi.org/10.4136/1980$\underline{993 X}$

NUNES, L. G. P.. Qualidade da Água no Município De São Mateus: Análise Parasitológica, Microbiológica E Físicoquímica. Dissertação (Mestrado em Ciências Farmacêuticas) - Universidade Federal do Espírito Santo, Vitória, 2018.

RICHTER, C. A; NETTO, J. M. A.. Tratamento de água: tecnologia atualizada. São Paulo: Edgard Blücher, 2013.

TORTORA, G. J.; CASE, C. L.; FUNKE, B. R.. Microbiologia. 10 ed. Porto Alegre: Artmed, 2012.

WALDMAN, M.. Lixo domiciliar brasileiro: Modelos de gestão e impactos Ambientais: Boletim Goiano de Geografia. Goiânia: UFG, 2013. DOI: https://doi.org/10.5216/bgg.33i2.25553

A CBPC - Companhia Brasileira de Produção Científica (CNPJ: 11.221.422/0001-03) detém os direitos materiais desta publicação. Os direitos referem-se à publicação do trabalho em qualquer parte do mundo, incluindo os direitos às renovações, expansões e disseminações da contribuição, bem como outros direitos subsidiários. Todos os trabalhos publicados eletronicamente poderão posteriormente ser publicados em coletâneas impressas sob coordenação da Sustenere Publishing, da Companhia Brasileira de Produção Científica e seus parceiros autorizados. Os (as) autores (as) preservam os direitos autorais, mas não têm permissão para a publicação da contribuição em outro meio, impresso ou digital, em português ou em tradução. 